\title{
Calcite Mineral Catalyst Capable of Enhancing Micropollutant Degradation during the Ozonation Process at $\mathrm{pH} 7^{+}$
}

\author{
Savvina Psaltou ${ }^{1}$, Efthimia Kaprara ${ }^{2}$, Manassis Mitrakas ${ }^{2}$ and Anastasios Zouboulis ${ }^{1, *}$ \\ 1 Division of Chemical and Environmental Technology, Department of Chemistry, Aristotle University, \\ 54124 Thessaloniki, Greece; spsaltou@chem.auth.gr \\ 2 Division of Analytical Chemistry, Department of Chemical Engineering, Aristotle University, \\ 54124 Thessaloniki, Greece; kaprara@auth.gr (E.K.); manasis@eng.auth.gr (M.M.) \\ * Correspondence:zoubouli@chem.auth.gr \\ + Presented at the 4th EWaS International Conference: Valuing the Water, Carbon, \\ Ecological Footprints of Human Activities, Online, 24-27 June 2020.
}

Published: 14 August 2020

\begin{abstract}
Catalytic ozonation is an Advanced Oxidation Process (AOPs) based on the production of hydroxyl radicals, which are very reactive oxidative species. The aim of this study is to evaluate the catalytic activity of calcite on the ozonation of four different typical micropollutants (atrazine, benzotriazole, carbamazepine, and $\mathrm{p}-\mathrm{CBA})$ at $\mathrm{pH} 7$ and for low initial concentrations $(4 \mu \mathrm{M})$ by performing batch mode experiments. These compounds have different physico-chemical characteristics, as well as different rate constants, when reacting with ozone and hydroxyl radicals $(\bullet \mathrm{OH})$, being in the range of $<0.15-3 \times 10^{5} \mathrm{M}^{-1} \mathrm{~s}^{-1}$ and $2.4-8.8 \times 109 \mathrm{M}^{-1} \mathrm{~s}^{-1}$, respectively. It was found that most of these micropollutants can be sufficiently removed by the application of heterogeneous catalytic ozonation, using calcite as the catalyst, except for the case of atrazine, which was the compound that was most difficult to degrade, when compared to the application of single ozonation. Carbamazepine with $\mathrm{ko}_{3}=3 \times 10^{5} \mathrm{M}^{-1} \mathrm{~s}^{-1}$ can be easily removed even by single ozonation after the first minute of the reaction time, and the addition of the catalyst eliminated the oxidation/reaction time. The application of catalytic ozonation resulted in $50 \%$ and $68.2 \%$ higher removals of benzotriazole and p-CBA, respectively, in comparison with single ozonation, even during the first $3 \mathrm{~min}$ of the reaction/oxidation time, due to the higher production of hydroxyl radicals, caused by the catalytic ozonation. For the case of atrazine, the addition of calcite did not enhance the micropollutant degradation, and its removal reached $83 \%$ after a $30 \mathrm{~min}$ application of catalytic ozonation, whereas during the single ozonation, the removal under the same reaction time was $90 \%$.
\end{abstract}

Keywords: heterogeneous catalytic ozonation; calcite; micropollutants; advanced oxidation process; water treatment

\section{Introduction}

Emerging contaminants (ECs) are usually organic toxic compounds that can be found in the environment at concentrations between ng/L and $\mu \mathrm{g} / \mathrm{L}$ [1]. Due to their occurrence at these low concentrations, these compounds are also referred to as micropollutants (MPs) [2]. MPs are usually contained in several consumer products, with the aim to improve human life, but at the same time, they may pose a serious threat to human health and to the ecosystem [3]. The main source of emerging pollutants in the aquatic environment is wastewater treatment effluents. The conventional wastewater treatment plants have not been designed to effectively remove the currently existing refractory organic compounds, and therefore, micropollutants can be discharged, largely untreated, 
into the nearby surface waters [4]. The development of advanced analytic techniques helped to identify these compounds, and hence, their efficient removal from wastewater treatment systems is now considered an important issue [1].

The applicable methods for the removal of micropollutants can be divided into three main categories: (1) phase-change processes, (2) biological processes, and (3) advanced oxidation processes (AOPs).The published research shows that AOPs are considered as the most efficient methods for the degradation of micropollutants [5]. Catalytic ozonation also belongs to these methods, which can be divided into homogeneous (using several transition metal ions as the catalysts) and heterogeneous (using appropriate solid materials as the catalysts). Catalytic ozonation is based on the degradation of toxic/refractory organic compounds through the decomposition of ozone into hydroxyl radicals $(\cdot \mathrm{OH})$, which are powerful, but non-selective oxidant agents [6]. The behavior of micropollutants during the ozonation process can be categorized into three groups, according to the respective reaction rate constants with ozone: ozone-resistant compounds, moderately ozone-reactive compounds, and high-to-moderate ozone-reactive compounds [7].

The aim of this study is to evaluate the catalytic efficiency of calcite during the heterogeneous catalytic ozonation process by evaluating the removal of four typical, low concentration $(4 \mu \mathrm{M})$ micropollutants, which belong to the three aforementioned categories, i.e., atrazine (ozone-resistant compound) [8], benzotriazole (moderately ozone-reactive compound) [9], carbamazepine (high-tomoderate-reactive ozone compound) [10], and p-CBA (ozone-resistant compound) [11]. Among them, p-CBA was used as a model compound, regarding the indirect evaluation of the hydroxyl radicals' production, to confirm if calcite (used as a catalyst) can promote the oxidation reaction rate via an improved radical mechanism. Several studies have shown that a positively-charged material can enhance the production of hydroxyl radicals during heterogeneous catalytic ozonation.

\section{Materials and Methods}

All chemicals were of analytical grade, except from the HPLC-grade acetonitrile (Chem-lab, Zedelgem, Belgium) and phosphoric acid (Sigma-Aldrich, St. Louis, MO, USA). Atrazine, benzotriazole, carbamazepine, and p-CBA (Sigma-Aldrich, St. Louis, MO, USA) were used as typical/model organic compounds at initial concentrations of $4 \mu \mathrm{M}$. Usually, micropollutants occur in a water environment at concentrations ranging from 10-11,600ng/L [3]. However, in some cases, organic compounds like caffeine can be found in concentrations around $0.3 \mathrm{mg} / \mathrm{L}$ [12]. All the solutions were prepared with distilled water. Calcite was used as a common catalyst. $\mathrm{K}_{2} \mathrm{HPO}_{4}$ and $\mathrm{KH}_{2} \mathrm{PO}_{4}$ dilute solutions (Chem-lab, Zedelgem, Belgium) were used to adjust the $\mathrm{pH}$ level to 7 , a common value for water and municipal wastewater effluents.

Adsorption, ozonation, and catalytic ozonation experiments were performed in batch mode, following the procedure described by Psaltou et al., 2018 [13]. The residual concentrations of micropollutants were determined by HPLC (Thermo, USA) with a UV detector at $254 \mathrm{~nm}$ (Thermo, UV2000). The mobile phase consisted of $10 \mathrm{mM}$ phosphoric acid and acetonitrile in the percentages shown in Table 1. The detection limit of the micropollutants was $0.025 \mu \mathrm{M}$. The concentration of ozone in aqueous solutions was determined by the common indigo method [14]. The major physico-chemical properties of calcite, i.e., the surface area, the pore size distribution (Brunauer-Emmet-Teller (BET) method), and the point of zero charge ( $\mathrm{pH}_{\mathrm{pzc}}$ ) (potentiometric mass titration method) were appropriately determined [15].

Table 1. Mobile phase proportions for the micropollutant detection by HPLC.

\begin{tabular}{|c|c|c|}
\hline Micropollutant & $\begin{array}{c}10 \mathrm{mM} \mathrm{H}_{3} \mathrm{PO}_{4} \\
(\% v / v)\end{array}$ & $\begin{array}{c}\mathrm{ACN} \\
(\% v / v) \\
\end{array}$ \\
\hline Atrazine & 50 & 50 \\
\hline Benzotriazole & 75 & 25 \\
\hline Carbamazepine & 60 & 40 \\
\hline p-CBA & 60 & 40 \\
\hline
\end{tabular}




\section{Results}

To evaluate the efficiency of calcite as a catalyst in the heterogeneous catalytic ozonation process, p-CBA was used as a convenient model compound. Other micropollutants that were examined in this study were atrazine, benzotriazole, and carbamazepine. In Table 2, the major physicochemical characteristics of these micropollutants, as well as their kinetic constants, regarding the reaction rates with ozone and hydroxyl radicals are also shown. Calcite is a mineral consisting of almost $100 \%$ $\mathrm{CaCO}_{3}$. The surface area and pore size were $6.3 \mathrm{~m}^{2} / \mathrm{g}$ and $0.038 \mathrm{~mL} / \mathrm{g}$, respectively. The point of zero charge of calcite was found to be 9.7 .

Table 2. Micropollutants used in this study as model/typical compounds and their properties (information collected with the help of the software program Chemicalize).

\begin{tabular}{|c|c|c|c|c|c|c|}
\hline Micropollutant & Structure & MW & Log D at pH 8 & $\mathrm{pK}_{\mathrm{a}}$ & ko3 $\left(M^{-1} s^{-1}\right)$ & $\mathbf{k} \cdot \mathrm{OH}\left(\mathbf{M}^{-1} \mathbf{s}^{-1}\right)$ \\
\hline Atrazine & & 215.7 & 2.20 & 3.2 & $6[8]$ & $2.4 \times 10^{9}[16]$ \\
\hline Benzotriazole & & 119.1 & 1.21 & 9.04 & $20[9]$ & $7.6 \times 10^{9}[16]$ \\
\hline Carbamazepine & & 236.3 & 2.77 & 16 & $3 \times 10^{5}[10]$ & $8.8 \times 10^{9}[16]$ \\
\hline $\mathrm{p}-\mathrm{CBA}$ & & 156.6 & -1.15 & 4.07 & $0.15[11]$ & $5 \times 10^{9}[16]$ \\
\hline
\end{tabular}

\subsection{Adsorption of Micropollutants by Calcite}

The adsorption capacity of calcite, regarding the atrazine, benzotriazole, carbamazepine, and p-CBA organic compounds, is presented in Table 3. The opposite charge between the solid material (IEP) and the organic compound ( $\mathrm{pK}_{\mathrm{a}}$ ) favors the affinity between them in the adsorption process. The isoelectric point of calcite is about eight [17]; hence it was positively charged at $\mathrm{pH}$ 7, where the oxidation reaction took place. From these micropollutants, two of them were positively charged (benzotriazole, carbamazepine), and the others were negatively charged (atrazine, p-CBA). Because of that, calcite showed a higher uptake capacity for atrazine $(289.0 \mu \mathrm{g} / \mathrm{g})$ than for benzotriazole and carbamazepine. The lowest adsorption capacity was determined in the case of $\mathrm{p}$-CBA, due to the nature of this organic molecule $\left(\mathrm{K}_{\mathrm{oc}}=42\right)$, which makes it rather difficult to be adsorbed in a solid surface [18].

Table 3. Adsorption loading of micropollutants $\left(\mathrm{C}_{0}=4 \mu \mathrm{M}\right)$ onto calcite $\left(\mathrm{C}_{\mathrm{cal}}=0.5 \mathrm{~g} / \mathrm{L}\right)$.

\begin{tabular}{ccccc}
\hline Parameter & Atrazine & Benzotriazole & Carbamazepine & p-CBA \\
\hline $\mathrm{q}(\mu \mathrm{g} \mathrm{MP} / \mathrm{g}$ calcite $)$ & 289.0 & 59.6 & 104.0 & 55.3 \\
\hline
\end{tabular}

\subsection{Calcite as a Catalyst in Heterogeneous Catalytic Ozonation}

The objective of this study was to evaluate the catalytic activity of calcite against four micropollutants, having different properties. Figures $1 \mathrm{a}$ and $2 \mathrm{a}$ show the results of their decomposition obtained by ozone oxidation during the application of single ozonation and of heterogeneous catalytic ozonation at $\mathrm{pH}$ 7. The presence of calcite was found to increase ozone decomposition, when compared to single ozonation experiments for all the examined micropollutants; however, with a different ozone decomposition rate. Carbamazepine with the ozone reaction constant equal to $3 \times 10^{5} \mathrm{M}^{-1} \mathrm{~s}^{-1}$ [10] reacts very fast with the ozone molecules, and hence, the respective consumption of ozone was high both in the single and in the catalytic ozonation experiments, reaching $94.5 \%$ and $97 \%$, respectively, even within the first minute of the 
reaction/oxidation time. The highest ozone degradation difference between the two ozonation processes was found during p-CBA's degradation, being $61.3 \%$ after $3 \mathrm{~min}$ of the treatment process.

The removal of micropollutants was found to show a similar behavior as the decomposition of ozone. The concentration of p-CBA decreased generally in parallel with the decreasing of the ozone concentration during either single or catalytic ozonation. p-CBA cannot be efficiently removed by the application of direct ozonation $\left(\mathrm{ko}_{3}<0.15 \mathrm{M}^{-1} \mathrm{~s}^{-1}\right)$ [11], whereas this compound presents high reactivity with hydroxyl radicals $\left(\mathrm{k} \bullet \mathrm{OH}=5 \times 10^{9} \mathrm{M}^{-1} \mathrm{~s}^{-1}\right)$ [16]. p-CBA degraded quickly even during the first minute, regarding the application of both processes, and then, the rate of its removal became smaller up to the respective reaction termination.

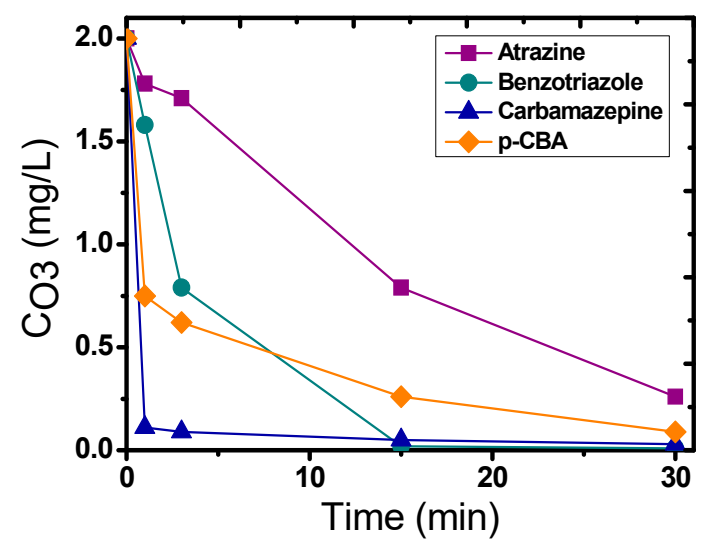

(a)

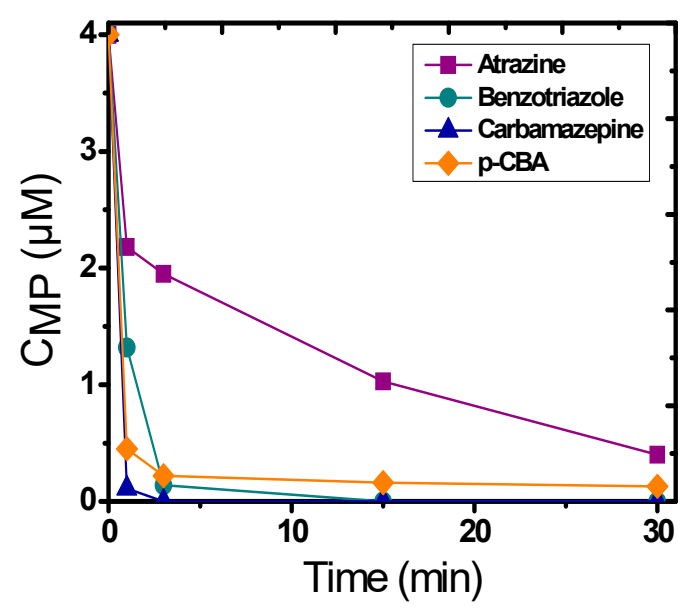

(b)

Figure 1. Micropollutant degradation by simple ozonation: (a) ozone decomposition; (b) degradation of micropollutants (MPs); experimental conditions: $\mathrm{CO}_{3}=2 \mathrm{mg} / \mathrm{L}, \mathrm{CMP}=4 \mu \mathrm{M}, \mathrm{pH}=7, \mathrm{~T}=23 \pm 2{ }^{\circ} \mathrm{C}$. 


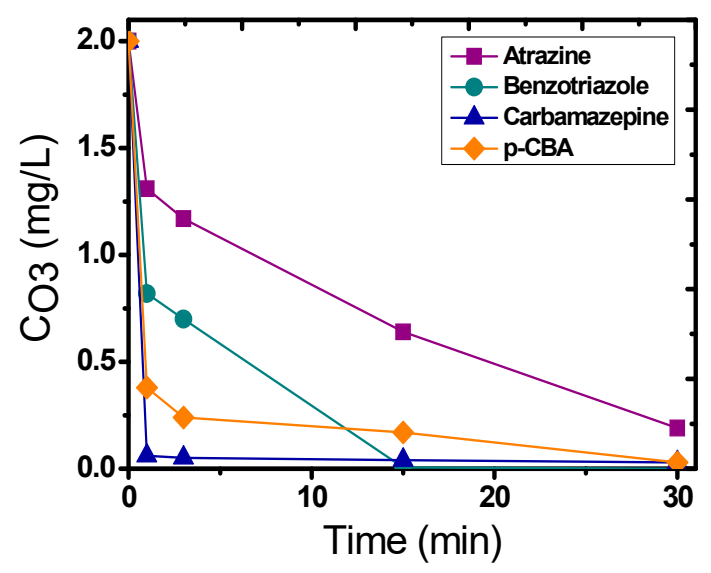

(a)

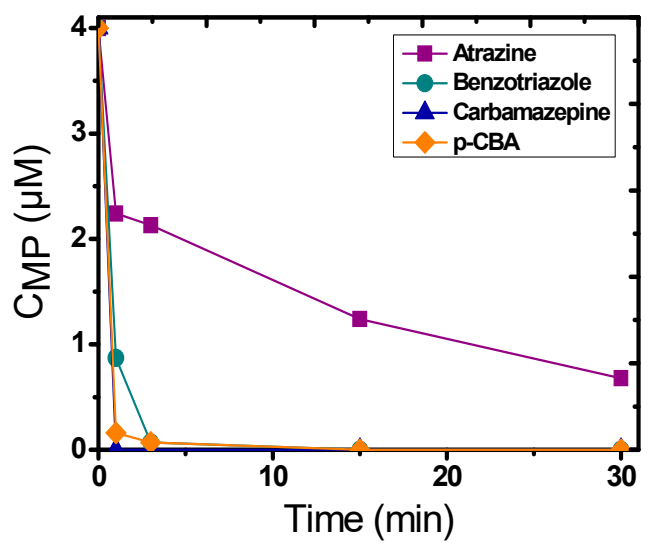

(b)

Figure 2. Micropollutant degradation by the application of heterogeneous catalytic ozonation, using calcite as the catalyst:(a) ozone decomposition; (b) degradation of MPs; experimental conditions: $\mathrm{CO}_{3}=2 \mathrm{mg} / \mathrm{L}, \mathrm{CMP}_{\mathrm{MP}}=4 \mu \mathrm{M}, \mathrm{C}_{\text {cal }}=0.5 \mathrm{~g} / \mathrm{L}, \mathrm{pH}=7, \mathrm{~T}=23 \pm 2{ }^{\circ} \mathrm{C}$.

As shown in Figure 1b, carbamazepine presented high reactivity with ozone (Table 2), as this compound was quickly degraded during the ozonation process, regardless of the presence of the catalyst (calcite). Furthermore, benzotriazole was efficiently removed by applying either single or catalytic ozonation, and its concentration was below the respective detection limit $(0.025 \mu \mathrm{M})$ after the $15^{\text {th }}$ and third minute of the reaction/oxidation time, respectively. In the third minute, the removal efficiency of benzotriazole using the catalytic ozonation system was 50\% higher than that of single ozonation. On the other hand, atrazine and p-CBA, with reaction rate constants with ozone lower than $6 \mathrm{M}^{-1} \mathrm{~s}^{-1}$ (Table 2), were removed at considerably lower kinetic rates during the single ozonation with the final removal efficiency (after the 30min treatment time) being $90 \%$ and $96.8 \%$, respectively. The difference between these compounds was due to the presence of calcite (acting as the catalyst), which seemed to favor only the degradation of p-CBA (showing $68 \%$ acceleration after the third minute of treatment time), while the removal of atrazine reached $83 \%$ upon the termination (i.e., after $30 \mathrm{~min}$ ) of the heterogeneous catalytic ozonation (Figure $2 \mathrm{~b}$ ). The decomposition of ozone in the presence of atrazine was rather slow in both processes (Figures 1a and 2a), and after 30 min of reaction time, there were still ozone and hydroxyl radical residuals in the system that could still degrade atrazine. Atrazine, despite its low reaction constant with ozone, also has the lowest reaction rate constant with hydroxyl radicals $\left(\mathrm{k} \bullet \bullet_{\mathrm{OH}}=2.4 \times 10^{9} \mathrm{M}^{-1} \mathrm{~s}^{-1}\right)$ [8]; therefore, it is rather difficult to totally remove, when compared to the other examined organic compounds. 


\section{Discussion}

Micropollutants are toxic and refractory organic compounds, which occur in ecosystems in small concentrations, ranging from $\mathrm{ng} / \mathrm{L}$ to $\mu \mathrm{g} / \mathrm{L}$. They can be categorized according to the ease of their removal through reactions with ozone as high/moderate and moderately ozone-reactive micropollutants or ozone-resistant compounds [7]. In the present study, the removal rates of four different micropollutants that belong to the different aforementioned categories were examined. Carbamazepine with a $3 \times 10^{5} \mathrm{M}^{-1} \mathrm{~s}^{-1}$ reaction rate constant with ozone [10] is a high ozone-reactive micropollutant, and it can be rather easily removed, regardless of calcite's presence in the ozonation system, as observed by other researches $[19,20]$. Benzotriazole is a moderately ozone-reactive compound $\left(\mathrm{ko}_{3}=20 \mathrm{M}^{-1} \mathrm{~S}^{-1}\right)$ [9], which can be degraded by applying both single or catalytic ozonation, but the application of catalytic ozonation can decrease the required oxidation treatment time. On the other hand, p-CBA and atrazine are both ozone-resistant organic compounds (Table 1), and their degradation cannot be successful quantitatively by the application of single ozonation (achieved removals $96.8 \%$ and $90 \%$, respectively), as in the case of carbamazepine and benzotriazole. The difference between the two ozone-resistant compounds is that while p-CBA has a lower ozone reaction rate constant than atrazine, it presented higher removal rates by applying both single and catalytic ozonation. Atrazine has the lowest reaction rate constant with hydroxyl radicals $\left(\mathrm{k} \cdot \mathrm{OH}=2.4 \times 10^{9} \mathrm{M}^{-1} \mathrm{~s}^{-1}\right)$; therefore, the expected acceleration in the production of hydroxyl radicals via the catalytic ozonation was not found to substantially influence the removal of atrazine. p-CBA, having twice the respective $\mathrm{k} \bullet$ oн value of atrazine, can be removed by almost $100 \%$ after the $3 \mathrm{~min}$ application of catalytic ozonation. Similar results for atrazine were shown by Fan et. al. [21]. The decomposition of ozone in the presence of atrazine is rather slow and, subsequently, so is the (slower) production of hydroxyl radicals. A catalyst can decompose ozone due to its specific structure, increasing the production of hydroxyl radicals, but a part of the oxidants can be also adsorbed by its surface, instead of the desired reaction with the organic pollutants. As a result, the amount of available ozone in the catalytic ozonation system would decrease, in comparison with the case of single ozonation, and the total decomposition of atrazine was inhibited.

Adsorption can be an important procedure for the promotion of the catalytic effect $[22,23]$, but it cannot be used for comparisons, regarding efficiency, in the case of different micropollutants' degradation, because the respective reaction rate constants with the oxidants still play a predominant role. The opposite charge between the catalyst and the atrazine/p-CBA may favor their contact and probably enhances their removal during the catalytic ozonation. However, their lower reaction constant, when reacting with ozone or with hydroxyl radicals, in comparison with carbamazepine and benzotriazole, overshadows the role of adsorption in catalytic ozonation. Therefore, preliminary adsorption experiments were conducted in this study, attempting to eliminate the possibility that calcite can act as simple adsorbent media and not as a catalyst, improving the oxidation of MPs by ozonation.

\section{Conclusions}

The heterogeneous catalytic ozonation using calcite as a common, in expensive catalyst for the improvement of micropollutant oxidation/degradation was examined for aqueous solutions of atrazine, benzotriazole, carbamazepine, and p-CBA, and it was found to be capable of increasing their degradation rates, as compared to single ozonation, except for the case of atrazine. After $30 \mathrm{~min}$ of catalytic ozonation treatment, eighty-three percent of atrazine was removed, while at the same time, the efficiency of single ozonation was $90 \%$. However, the presence of calcite was found to enhance p-CBA removal, which indicates (indirectly) that calcite can accelerate the production of hydroxyl radicals. Therefore, calcite can be characterized as a catalyst in the process of heterogeneous catalytic ozonation. The removal of benzotriazole and p-CBA reached $98.3 \%$ at the third minute of the reaction/oxidation time, while at the same time, the concentration of carbamazepine was under the analytical method detection limit $(0.025 \mu \mathrm{M})$.From the results of this study, it is obvious that, although calcite can be considered as a catalyst, its efficiency to improve the removal of different 
micropollutants mainly depends on the specific properties of the organic compounds applied and, in particular, on the $\mathrm{pK}$ a values and the respective rate constants with the oxidant agents.

Author Contributions: Conceptualization, S.P., A.Z. and M.M.; methodology, S.P.; validation, S.P. and M.M.; investigation, S.P. and E.K.; resources, A.Z. and M.M.; data curation, S.P. and E.K.; writing, original draft preparation, S.P.; writing, review and editing, A.Z., M.M. and E.K.; visualization, S.P.; supervision, A.Z. and M.M.; project administration, A.Z.; funding acquisition, A.Z. All authors read and agreed to the published version of the manuscript.

Funding: This research was co-financed by the European Union and Greek national funds through Operational Program Competitiveness, Entrepreneurship and Innovation, under the call RESEACH-CREATE- INNOVATE (project code: T1EDK-02397).

Conflicts of Interest: The authors declare no conflict of interest.

\section{References}

1. Kapelewska, J.; Kotowska, U.; Karpi, J.; Kowalczuk, D.; Arciszewska, A.; Anna, Ś. Occurrence, removal, mass loading and environmental risk assessment of emerging organic contaminants in leachates, groundwaters and wastewaters. Microchem. J. 2018, 137, 292-301, doi:10.1016/j.microc.2017.11.008.

2. Wang, J.; Tian, Z.; Huo, Y.; Yang, M.; Zheng, X.; Zhang, Y. Monitoring of 943 organic micropollutants in wastewater from municipal wastewater treatment plants with secondary and advanced treatment processes. J. Environ. Sci. 2018, 67, 309-317, doi:10.1016/j.jes.2017.09.014.

3. Kim, M.K.; Zoh, K.D. Occurrence and removals of micropollutants in water environment. Environ. Eng. Res. 2016, 21, 319-332, doi:10.4491/eer.2016.115.

4. Petrie, B.; Barden, R.; Kasprzyk-Hordern, B. A review on emerging contaminants in wastewaters and the environment : Current knowledge, under studied areas and recommendations for future monitoring. Water Res. 2014, 72, 3-27, doi:10.1016/j.watres.2014.08.053.

5. Rodriguez-Narvaez, O.M.; Peralta-Hernandez, J.M.; Goonetilleke, A.; Bandala, E.R. Treatment technologies for emerging contaminants in water: A review. Chem. Eng. J. 2017, 323, 361-380, doi:10.1016/j.cej.2017. 04.106.

6. Nawrocki, J. Catalytic ozonation in water: Controversies and questions. Discussion paper. Appl. Catal. B Environ. 2013, 142, 465-471, doi:10.1016/j.apcatb.2013.05.061.

7. Guo, Y.; Wang, H.; Wang, B.; Deng, S.; Huang, J.; Yu, G.; Wang, Y. Prediction of micropollutant abatement during homogeneous catalytic ozonation by a chemical kinetic model. Water Res. 2018, 142, 383-395, doi:10.1016/j.watres.2018.06.019.

8. Yang, J.; Li, J.; Dong, W.; Ma, J.; Cao, J.; Li, T.; Li, J.; Gu, J.; Liu, P. Study on enhanced degradation of atrazine by ozonation in the presence of hydroxylamine. J. Hazard. Mater. 2016, 316, 110-121, doi:10.1016/j.jhazmat. 2016.04.078.

9. Roshani, B.; McMaster, I.; Rezaei, E.; Soltan, J. Catalytic ozonation of benzotriazole over alumina supported transition metal oxide catalysts in water. Sep. Purif. Technol. 2014, 135, 158-164, doi:10.1016/j.seppur. 2014.08.011.

10. Rosal, R.; Rodríguez, A.; Gonzalo, M.S.; García-Calvo, E. Catalytic ozonation of naproxen and carbamazepine on titanium dioxide. Appl. Catal. B Environ. 2008, 84, 48-57, doi:10.1016/j.apcatb.2008.03.003.

11. Lan, B.; Huang, R.; Li, L.; Yan, H.; Liao, G.; Wang, X.; Zhang, Q. Catalytic ozonation of p-chlorobenzoic acid in aqueous solution using Fe-MCM-41 as catalyst. Chem. Eng. J. 2013, 219, 346-354, doi:10.1016/j.cej. 2012.12.083.

12. Kosma, C.I.; Lambropoulou, D.A.; Albanis, T.A. Investigation of PPCPs in wastewater treatment plants in Greece: Occurrence, removal and environmental risk assessment. Sci. Total Environ. 2014, 466, 421-438.

13. Psaltou, S.; Stylianou, S.; Mitrakas, M.; Zouboulis, A.I. Heterogeneous Catalytic Ozonation of pChlorobenzoic Acid in Aqueous Solution by FeMnOOH and PET. Separations 2018, 5, 42, doi:10.3390/ separations5030042.

14. Clesceri, S.L.; Greenberg, .E.A.; Trussel, R.R. Standard Methods for Examination of Water and Wastewater, 17th ed.; Inorganic Nonmetals; American Public Health Association: Washington, DC, USA, 1989; pp. 162-165, ISBN 087553-161-X.

15. Kosmulski, M. Surface Charging and Points Zero Charge; CRC: Boca Raton, FL, USA, 2009; p. 145, ISBN 978-1-420051889-9. 
16. Mandal, S. Reaction Rate Constants of Hydroxyl Radicals with Micropollutants and Their Significance in Advanced Oxidation Processes. J. Adv. Oxid. Technol. 2018, 21, doi:10.26802/jaots.2017.0075.

17. Fuerstenau, M.C.; Han, K.N. (Eds.) Principles of Mineral Processing, Society for Mining, Metallurgy, and Exploration;Inc. (SME): Littleton, CO, USA, 2003; Volume 18, ISBN 0-87335-167-3.

18. Pines, D.S.; Reckhow,D.A. Solid Phase Catalytic Ozonation Process for the Destruction of a Model Pollutant.Ozone Sci. Eng. 2016, 5, 25-39, doi:10.1080/713610648.

19. Andreozzi, R.; Marotta, R.; Pinto, G.; Pollio, A. Carbamazepine in water: Persistence in the environment, ozonation treatment and preliminary assessment on algal toxicity. Water Res. 2002, 36, 2869-2877.

20. Aguilar, C.M.; Vazquez-arenas, J.; Castillo-araiza, O.O.; Rodríguez, J.L.; Salinas, E.; Poznyak, T. Improving ozonation to remove carbamazepine through ozone-assisted catalysis using different $\mathrm{NiO}$ concentrations. Environ. Sci. Pollut. Res. 2020,27, 22184-22194.

21. Fan, X.; Restivo, J.; Órfão, J.J.M.; Fernando, M.; Pereira, R.; Lapkin, A.A. The role of multiwalled carbon nanotubes (MWCNTs) in the catalytic ozonation of atrazine. Chem. Eng. J. 2014, 241, 66-76, doi:10.1016/ j.cej.2013.12.023.

22. Kermani, M.; Kakavandi, B.; Farzadkia, M.; Esrafili, A.; Jokandan, S.F.; Shahsavani, A. Catalytic ozonation of high concentrations of catechol over $\mathrm{TiO}_{2} @ \mathrm{Fe}_{3} \mathrm{O}_{4}$ magnetic core-shell nanocatalyst: Optimization, toxicity and degradation pathway studies. J. Clean. Prod. 2018, 192, 597-607, doi:10.1016/j.jclepro.2018.04.274.

23. Shahama, Y.D.; Sadeghi, M.; Shahryari, A.; Okhovat, N.; Asl, F.B.; Baneshi, M.R. Heterogeneous catalytic ozonation of 2,4-dinitrophenol in aqueous solution by magnetic carbonaceous nanocomposite: catalytic activity and mechanism. Desalin. Water Treat. 2015, 57, 20447-20456.

(c) 2020 by the authors. Licensee MDPI, Basel, Switzerland. This article is an open access article distributed under the terms and conditions of the Creative Commons Attribution (CC BY) license (http://creativecommons.org/licenses/by/4.0/). 